\title{
Correction to: Evaluation of machine learning methods for predicting eradication of aquatic invasive species
}

\author{
Yanyu Xiao $\cdot$ Russell Greiner • Mark A. Lewis
}

Published online: 28 April 2018

(C) Springer International Publishing AG, part of Springer Nature 2018

\section{Correction to: Biol Invasions}

https://doi.org/10.1007/s10530-018-1715-2

Figure 6 was published incorrectly with an incorrect axis in the original publication. The correct version of Fig. 6 is provided in this correction.

The original article can be found online at https://doi.org/10.1007/s10530-018-1715-2.

Y. Xiao $(\bowtie)$

Department of Mathematical Sciences, University of Cincinnati, Cincinnati, OH 45221-0025, USA

e-mail: yanyu.xiao@uc.edu

R. Greiner

Department of Computing Science, University of Alberta, Edmonton, AB T6G 2E8, Canada

e-mail: rgreiner@ualberta.ca

M. A. Lewis

Center for Mathematical Biology, Department of Mathematical and Statistical Sciences, University of Alberta, Edmonton, AB T6G 2G1, Canada

e-mail: mark.lewis@ualberta.ca

M. A. Lewis

Department of Biological Sciences, University of Alberta, Edmonton, AB T6G 2E9, Canada 

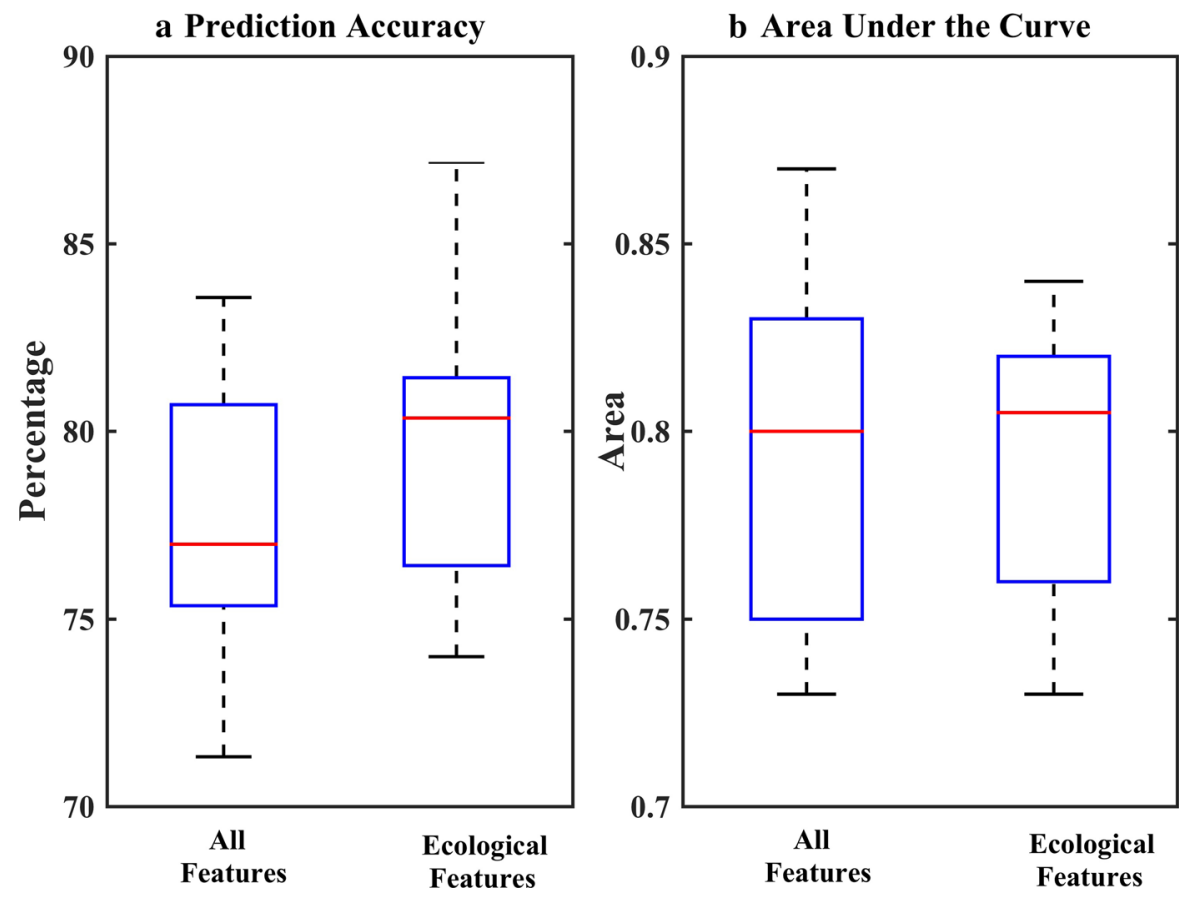

Fig. 6 Comparisons of the performance of six- and four-feature models 